\title{
Perumusan Strategi Bisnis untuk Peningkatan Market Share PT Terminal Teluk Lamong
}

\author{
Bibin Retmawan \\ Universitas Airlangga \\ e-mail: biretma@icloud.com
}

\begin{abstract}
The existence of a port really determines progress in an area, this is related to its function in the supply chain management distribution or logistic distribution system as a link between sea and land transportation modes to meet the needs of the community and industry which will ultimately affect economic growth in an area. Meeting the needs of the community will be fulfilled optimally, efficiently and effectively if the port as a logistical support system for the distribution of goods and people can run smoothly and well integrated. The purpose of this study is to analyze the right strategy at PT Terminal Teluk Lamong in winning the competition seen from the analysis of the internal environment and the analysis of the external environment. This research uses a qualitative approach with a case study approach. The sample of this research is key informants using purposive sampling and conducting interviews. The results of this study are that the Terminal PT Teluk Lamong is in a "hold and maintain" position. This is based on consideration of internal factors, external factors, and analysis of company position using the Internal-External Evaluation Matrix (IE Matrix). The result of internal factor evaluation (IFE) of PT Terminal Teluk Lamong is an average value of 2,339 IFE, which is in the average area. Whereas the results of the external factor evaluation (EFE) of PT Terminal Teluk Lamong are an average value of EFE of 2,554 , which is in the middle region. From the results of the IFE and IFE matrix, the PT Terminal Teluk Lamong position in the internal external matrix analysis is in quadrant $V$, namely in area II where the company is in a hold and maintain position.
\end{abstract}

Keywords: competitive strategy, SWOT, external analysis, internal analysis

\section{PENDAHULUAN}

Kondisi geografis PT Terminal Teluk Lamong yang terletak di daerah Tambak Osowilangon Benowo Surabaya memiliki keunikan tersendiri. Kondisi lingkungan baru dengan minimnya depo-depo petikemas dan gudang-gudang barang curah kering belum mendukung PT Terminal Teluk Lamong untuk berkembang menjadi terminal multipurpose. Tuntutan perusahaan induk PT Pelindo III (Persero) yang menginginkan PT Terminal Teluk Lamong untuk segera tumbuh dan berkembang sehingga lebih produktif merupakan catatan penting bagi manajemen agar PT Terminal Teluk Lamong bisa terus tumbuh dan meningkatkan pendapatan.
PT Pelindo III (Persero) memiliki beberapa anak perusahaan yang bergerak pada jasa terminal operator di Pelabuhan Tanjung Perak Surabaya, di antaranya Cabang Tanjung Perak, PT TPS (Terminal Petikemas Surabaya), PT BJTI (Berlian Jasa Terminal Indonesia) dan PT Terminal Teluk Lamong. Cabang Tanjung Perak merupakan cabang dari PT Pelindo III (Persero) atau yang dikenal dengan Pelindo III Cabang Tanjung Perak, merupakan pemegang hak HPL (Hak Pengelolaan Lahan) di Area Pelabuhan Tanjung Perak. Semua kegiatan Pemanduan dan Penundaan kapal-kapal yang sandar di semua terminal dalam wilayah area Pelabuhan Tanjung Perak menjadi kewenangan oleh Pelindo III Cabang 
Tabel Proporsi Trafik Petikemas dan Curah Kering Tahun 2018

\begin{tabular}{c|c|r|r|r|r|c}
\hline JUMLAH TRAFIK 2018 & SATUAN & \multicolumn{1}{|c|}{ TG Perak } & \multicolumn{1}{c|}{ BJTI } & \multicolumn{1}{c|}{ TPS } & \multicolumn{1}{c}{ TTL } & \multicolumn{1}{c}{ TOTAL } \\
\hline Petikemas Luar Negeri & Teus & 703 & - & 1.349 .587 & 321.977 & 1.672 .267 \\
\hline Petikemas Dalam Negeri & Teus & 544.985 & 1.224 .892 & 108.593 & 314.909 & 2.193 .379 \\
\hline Total Petikemas & Teus & $\mathbf{5 4 5 . 6 8 8}$ & $\mathbf{1 . 2 2 4 . 8 9 2}$ & $\mathbf{1 . 4 5 8 . 1 8 0}$ & $\mathbf{6 3 6 . 8 8 6}$ & $\mathbf{3 . 8 6 5 . 6 4 6}$ \\
\hline Total Curah Kering & Ton & $\mathbf{4 . 7 6 5 . 7 0 7}$ & $\mathbf{1 . 0 4 3 . 1 6 6}$ & - & $\mathbf{2 . 5 3 5 . 9 8 8}$ & $\mathbf{8 . 3 4 4 . 8 6 1}$ \\
\hline
\end{tabular}

Tanjung Perak. Sedangkan area labuh menjadi kewenangan dari otoritas pelabuhan sesuai Undang-Undang Pelayaran No. 17 Tahun 2008.

Pada tahun 2018, market share kegiatan bongkar muat petikemas dan curah kering di area pelabuhan Tanjung Perak sebagaimana tabel di atas. Dalam kegiatan bongkar muat petikemas, market share terbanyak dipegang oleh PT TPS sebesar $38 \%$ atau 1.458 .180 teus, posisi kedua dipegang oleh PT BJTI sebesar 32\% atau 1.224.892 teus, posisi ketiga adalah PT TTL sebesar $16 \%$ atau 636.886 teus, sedangkan $\mathrm{Tg}$ Perak sebesar $14 \%$ atau 545.688 teus. Sedangkan untuk kegiatan bongkar curah kering, sebanyak 57\% atau 4.765.707 Ton dimiliki oleh Cabang Tanjung Perak, PT TTL sebesar 30\% atau 2.535.988 Ton (naik hamper 100\% dari tahun sebelumnya) dan PT BJTI sebesar 13\% atau 1.043.166 Ton.

Bisnis terminal petikemas di area Pelabuhan Tanjung Perak sangat kompetitif dan untuk kegiatan curah kering dikuasai oleh Cabang Tanjung Perak. Dibutuhkan strategi bisnis yang tepat untuk dapat bersaing dan memilki keunggulan bersaing dalam industri kepelabuhanan. Kondisi PT Terminal Teluk Lamong sebagai pendatang baru di industri kepelabuhanan dapat dikatakan sebagai "Big Baby" (Prasetyadi, 2015). Penerapan teknologi terbaru dan semi-automatic di PT Terminal Teluk Lamong dalam semua kegiatan bongkar muat petikemas dan curah kering menuntut perubahan pola operasi baik di sisi terminal maupun di pelanggan. E-transaction (online transaction) dan e-payment merupakan hal baru bagi pengguna jasa di mana tidak ada lagi pengguna jasa datang ke kantor untuk proses pengurusan dokumen sehingga meminimalkan "face to face”. Pro dan kontra penggunaan teknologi dalam transaksi jasa kepelabuhan memiliki tantangan tersendiri bagi PT Terminal Teluk Lamong. Aroma pengguna jasa mempertahankan sistem lama (manual) sangat tinggi.

Capaian tersebut tidak terlepas dari beberapa strategi dan keunggulan yang telah terapkan oleh PT Terminal Teluk Lamong sehingga mampu menghasilkan capaian yang memang belum terbilang bagus, dan berharap ke depannya dapat lebih meningkatkan produktivitasnya. Keunggulan dari PT Terminal Teluk Lamong dibandingkan Terminal lain di area Pelabuhan Tanjung Perak atau bahkan di wilayah Indonesia yaitu pertama Auto Gate System, di mana pembacaan container sudah menggunakan alat yang di namakan OCR (Optical Character Recognition). Kedua No People in Pre-Gate and Main Gate, tidak ada pertukaran data menggunakan kertas (hardcopy) sehingga menambah kecepatan transaksi dan mengurangi adanya pungutan liar, semua transaksi dalam kegiatan di PT Terminal Teluk Lamong dilakukan secara online transaction. Ketiga Automation the truck read data, setiap truk yang masuk ke Terminal Teluk Lamong sudah dipasangi RFID card yang ditempelkan pada chasis dan head truk, hal ini dapat membantu kecepatan proses receiving delivery petikemas. Keempat Green Port, suprastruktur 
yang digunakan menggunakan alat-alat yang ramah lingkungan dengan penggunaan listrik sebagai mesin penggeraknya, dimulai dari STS (Ship to Shore), GSU (Grab Ship Unloader), ASC (Automatic Stacking Crane) dan beberapa alat bongkar muat lainnya termasuk penggunaan truk dengan bahan bakar Gas. Konsep ini menjadikan PT Terminal Teluk Lamong pelabuhan pertama di Indonesia yang ramah lingkungan. Kelima Docking System, container yang di angkut oleh truk CTT (Combine Truck Terminal) dapat dilakukan secara otomatis ke dalam docking area.

Strategi dengan konsep diferensiasi dalam penerapan strategi bisnis yang di kembangkan oleh PT Terminal Teluk Lamong di mana terdapat sistem layanan sangat berbeda dari terminal pesaing, mengutamakan konsep Green Port dan Automatic dalam segala layanan bongkar muat sehingga menciptakan keunikan tersendiri. Biaya yang dikeluarkan dalam menciptakan keunggulan tersebut tentunya tidak sedikit, akan tetapi hal tersebut tidak diimbangi dengan tarif bongkar muat yang sesuai dengan layanan yang diberikan. Penetapan tarif bongkar muat di area Pelabuhan Tanjung Perak ditentukan oleh Kantor Otorasi Pelabuhan yang berfungsi sebagai regulator Pelabuhan. Semua tarif bongkar muat petikemas dan curah kering memiliki tarif yang sama dan berlaku sama di semua terminal pada area Pelabuhan Tanjung Perak. Hal ini merupakan tantangan utama bagi PT Terminal Teluk Lamong untuk tetap tumbuh dan berkembang menghadapi persaingan bisnis terminal operator. Terlebih lagi tuntutan dari pemegang saham untuk mencapai target laba di tahun 2018 naik menjadi 300\%.

Dari hasil analisis tersebut perusahaan dapat mendiagnosis lingkungan dan mengambil suatu kebijakan strategis berdasarkan keunggulan dan kelemahan yang dimiliki serta mempertimbangkan peluang dan ancaman yang ada. Hal inilah yang mendorong dilakukannya penelitian dengan judul: Perumusan Strategi Bisnis untuk Peningkatan Market Share PT Terminal Teluk Lamong.

\section{TINJAUAN PUSTAKA}

\section{Strategi}

Strategi yaitu pencapaian jangka panjang yang hendak dicapai oleh perusahaan (David, 2011). Adanya penetrasi pasar, divestasi, likuidasi, ekspansi secara geografis merupakan salah satu cakupan dari strategi bisnis. Dalam mencapai tujuan dan sasaran perusahaan diperlukan sebuah tindakan yaitu sebuah strategi. Strategi artinya seni atau ilmu untuk menjadi seorang jenderal (Tjiptono, 2006). strategi merupakan potret dari rencana dalam skala besar di masa akan datang guna bisa bersaing dalam mencapai tujuan perusahaan (Pearce dan Robinson, 2008). Dilihat dari beberapa pengertian di atas, dapat disimpulkan bahwa pengertian strategi yaitu sebuah tindakan nyata dari perusahaan dalam mencapai tujuan perusahaan berdasarkan keputusan bersama dari para pimpinan yang disesuaikan dengan kebutuhan pelanggan.

Strategi merupakan sebuah perencanaan yang matang di mana bisa menjelaskan semua tujuan dan sasaran dari perusahaan berdasarkan visi dan misi dari perusahaan (Rangkuti, 2015). Konsep strategi menurut Stoner et al (2005) memiliki dua pemikiran berbeda yaitu pemikiran organisasi ingin dilakukan dan pemikiran organisasi yang akhirnya lakukan. Agar tujuan perusahaan yang efektif dan efisien tercapai maka diperlukan strategi yang tepat di mana ini merupakan unsur penting bagi perusahaan dalam mencapai sasarannya, selain itu perusahaan juga harus bisa menghadapi permasalahan yang semakin dinamis baik permasalahan secara internal dan eksternal. Konsep strategi memiliki 
THE IFE TOTAL WEIGHTED SCORES

\begin{tabular}{l|c|c|c|}
\multicolumn{1}{c}{ Strong } & Average & Weak \\
\cline { 2 - 4 } & \multicolumn{1}{c|}{ High } & II & III \\
\cline { 2 - 4 } Medium & IV & V & IX \\
\hline Low & VII & VIII & \\
\hline
\end{tabular}

\section{Gambar The Internal - External Matrix}

Sumber: David, F. R. 2003. Strategic Management: Concepts and Cases (13th ed.). New Jersey: Prentice Hall.

banyak perkembangan dalam definisinya. Perusahaan dalam mencapai visi dan misinya baik pencapaian jangka pendek dan jangka panjang membutuhkan namanya strategi.

\section{Analisis SWOT (Matriks EFE dan EFE)}

Internal-External (IE) Matrix merupakan alat analisis yang digunakan untuk mengetahui posisi suatu perusahaan, dengan menggabungkan hasil dari Internal Factor Evaluation (IFE) Matrix dan External Factor Evaluation (EFE) Matrix.

IE Matrix dapat dibagi menjadi tiga bagian besar yang memiliki implikasi strategi yang berbeda sebagai berikut.

a. Area pertama terdiri atas sel I, II, atau IV dapat dideskripsikan sebagai strategi grow and build. Strategi yang sesuai untuk tahap ini adalah strategi intensive (market penetration, market development, dan product de- velopment). Strategi lain yang dapat digunakan adalah strategi integrative (backward integration, forward integration, dan horizontal integration).

b. Area kedua terdiri dari sel III, V, atau VII dapat digambarkan sebagai strategi hold and maintain. Strategi yang sesuai untuk tahap hold and maintain adalah market penetration dan product development.

c. Area ketiga terdiri dari sel IV, VIII, atau IX dapat dideskripsikan sebagai strategi harvest atau divest.

\section{Strategi 3C}

Model 3C (Ohmae, 1995) menyatakan bahwa strategi harus fokus kepada 3 (tiga) faktor untuk mencapai kesuksesan. Ketiga faktor tersebut antara lain konsumen, perusahaan, dan kompetisi. 
3C model $\cdot$ Ohmae toolshero

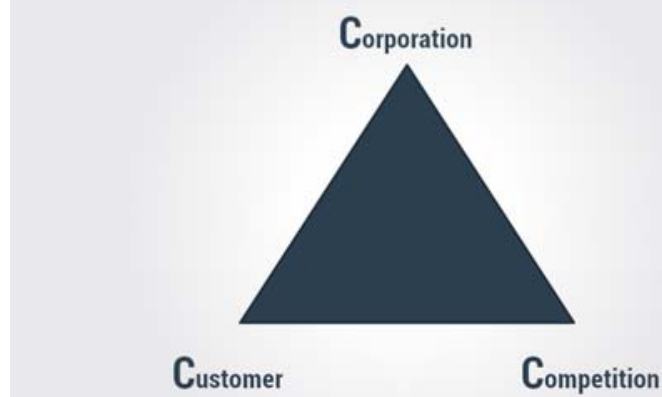

0300

Gambar Model 3C (Ohmae, 1995)

1. Strategi berdasarkan pendekatan perusahaan Strategi yang melibatkan perusahaan termasuk strategi dalam memilih. Hal ini berarti perusahaan tidak harus menjadi utama dalam segala lini. Namun ketika tidak memungkinkan, menjadi utama/pemimpin pasar dalam satu lini saja sudah cukup. Strategi kedua adalah strategi membuat atau membeli. Penentuan strategi ini didasarkan pendekatan biaya juga pendekatan apakah supplier mampu menghasilkan produk yang dibutuhkan dengan waktu yang telah ditetapkan. Strategi ketiga yang berkaitan dengan perusahaan adalah strategi minimalisasi biaya.

2. Strategi berdasarkan pendekatan konsumen Strategi ini dilakukan dengan mensegmentasi konsumen untuk mempermudah analisis pasar. Segmentasi yang pertama dilakukan dengan mensegmentasi konsumen berdasarkan tujuan penggunaan barang. Segmentasi kedua dilakukan dengan mensegmentasi konsumen berdasarkan area coverage, yakni membatasi pemasaran produk pada era yang termasuk distribusi produk. Ketiga pendekatan segmentasi pasar cenderung menurun, perusahaan juga dapat melakukan segmentasi ulang atas konsumen. Perubahan segmentasi tersebut bisa muncul karena perubahan customer mix, yang terdiri dari demografi, distribusi dan lain sebagainya.

3. Strategi berdasarkan pendekatan competitor Strategi yang paling penting dalam persaingan adalah menggunakan pendekatan diferensiasi, melalui desain pembelian, kualitas layanan dan penjualan. Oleh karenanya penting untuk menjaga image merek di mata konsumen untuk tetap bisa bersaing dengan kompetitor.

\section{PERUMUSAN MASALAH}

Berdasarkan uraian latar belakang permasalahan di dalam penelitian, maka pertanyaan penelitian yang akan dijawab melalui penelitian ini yaitu bagaimana analisis lingkungan dapat digunakan sebagai penentuan strategi pada PT Terminal Teluk Lamong?

\section{METODE PENELITIAN}

Pendekatan penelitian yang digunakan dalam penelitian ini adalah penelitian kualitatif. Secara spesifik penelitian ini adalah penelitian deskriptif kualitatif. Pendekatan kualitatif ini didefinisikan sebagai sebuah proses penyelidikan untuk memahami masalah sosial, yang didasarkan sebagai penciptaan secara holistis yang dapat dibentuk dengan kata-kata, serta memberikan pandangan dari pemberi informasi secara alami dan terperinci (Cresswell, 2015).

\section{Sampel dan Teknik Pengambilan Sampel}

Sampel yang digunakan dalam penelitian ini adalah key informan (informan kunci) yaitu orang-orang yang sangat memahami organisasi dan memiliki kepentingan sesuai dengan infor- 
masi yang dibutuhkan dalam penelitian ini. Penentuan informan kunci ditentukan menggunakan purposive sampling. Pada penelitian ini, akan dilakukan interview dengan beberapa key informan berdasarkan struktur organisasi PT Terminal Teluk Lamong, yaitu President Director, Director of Operation and Engineering, Director of General Affair and Finance, Senior Manager Pihak Eksternal di Lingkungan Terminal Teluk Lamong.

\section{Lokasi Penelitian}

Penelitian ini dilakukan di PT Terminal Teluk Lamong.

\section{Teknik Analisis}

Pengolahan data penelitian dapat dilakukan dengan beberapa tahapan yaitu: analisis lingkungan internal, analisis ini menjelaskan tentang analisis program pemasaran, analisis sumber daya manusia dan analisis keuangan. Analisis lingkungan eksternal, analisis mengenai faktor ekonomi, faktor pemerintah, faktor sosial budaya, faktor teknologi dan faktor persaingan. Analisis 3C yang menjelaskan tentang posisi perusahaan dalam Kenichi Ohmae yaitu: Corporation, Customer dan Competition. Analisis SWOT, Menentukan kekuatan, kelemahan, peluang, dan ancaman kemudian dibuat dalam bentuk tabel faktor-faktor kekuatan dan kelemahan dan faktor-faktor peluang dan ancaman. Analisis dan pembahasan strategi, dari hasil analisis lingkungan internal, analisis lingkungan eksternal, analisis lingkungan industri, dan analisis SWOT dapat diketahui hasil dari posisi akan menggunakan strategi apa yang dipilih.

\section{ANALISIS DAN PEMBAHASAN HASIL PENE- LITIAN}

\section{Analisis Faktor Internal}

Analisis faktor internal bertujuan untuk mengevaluasi faktor-faktor kekuatan dan kelemahan Terminal Teluk Lamong agar dapat digunakan sebagai penilaian terhadap kondisi internal perusahaan. Dalam menganalisis lingkungan internal dilakukan penyebaran kuesioner untuk responden yang telah dipilih, yang dirasa kompeten dalam menjawab pertanyaan-pertanyaan penelitian. Responden dari penelitian ini adalah dari jajaran manajerial Terminal Teluk Lamong. Jumlah keseluruhan yang dilakukan penelitian yaitu dari top level manager dan middle manager.

Faktor internal mencakup kelemahan dan kekuatan yang dimiliki oleh perusahaan. Dari hasil wawancara pada tahap pra analisis, maka diidentifikasi variabel-variabel yang kemudian akan di analisis dalam internal evaluation factor (IFE). Faktor internal yang menjadi kelemahan yang dimiliki Terminal Teluk Lamong antara lain: letak geografis luar area Tanjung Perak, keterbatasan kapasitas dermaga (under capacity dermaga), maintenance support equipment availability alat operasional, maintain terkait kemampuan pegawai ditingkatkan, rotasi kerja pada beberapa bidang pekerjaan, belum adanya backup listrik secara optimal, kegagalan sistem apabila listrik down, dan regulasi dalam penentuan tarif petikemas.

Berikut adalah faktor internal yang menjadi kekuatan yang dimiliki Terminal Teluk Lamong: Branding TTL sebagai terminal petikemas berbasis teknologi, peralatan berbasis semi otomatis, integrasi sistem dengan pihak regulator, pengguna jasa dan bea cukai, Fleksibilitas layanan 24 jam 7 hari, Efisiensi transaksi pelanggan secara on- 
line, kecepatan pelayanan bongkar muat, dan sumber daya manusia dalam golongan milenial (usia produktif).

Selanjutnya, analisis dilakukan dengan memberikan bobot dan rating pada variabel-variabel yang termasuk dalam faktor internal. Bobot total untuk bobot internal bernilai maksimal 1 . Bobot yang tinggi menggambarkan tingkat kepentingan indikator tersebut, dan sebaliknya bobot yang rendah menggambarkan kepentingan yang rendah dari indikator tersebut. Dilihat dari jawaban responden matriks internal faktor evaluation (IFE) maka dapat dianalisis sebagian besar responden berpendapat bahwa Terminal Teluk Lamong belum memiliki strategi yang efektif terhadap faktor-faktor internal. Ratarata pada bobot matriks IFE maka hasilnya 2.339, di mana nilai bobot tersebut berada pada wilayah rata-rata atau cukup, yang berarti strategi yang diterapkan oleh Terminal Teluk Lamong masih belum optimal untuk dapat bersaing dalam industri bongkar muat.

\section{Analisis Faktor Eksternal}

Analisis faktor eksternal bertujuan untuk mengevaluasi faktor-faktor tantangan dan peluang yang dihadapi oleh Terminal Teluk Lamong agar dapat digunakan sebagai penilaian terhadap kondisi eksternal perusahaan. Dalam menganalisis lingkungan eksternal dilakukan penyebaran kuesioner untuk responden yang telah dipilih, yang dirasa kompeten dalam menjawab pertanyaan-pertanyaan penelitian. Faktor eksternal mencakup tantangan serta peluang yang dihadapi oleh perusahaan. Hasil dari proses wawancara pada tahap pra analisis dengan responden eksternal, maka diperoleh variabel-variabel yang kemudian dimasukkan ke dalam external factor evaluation (EFE).
Faktor eksternal yang menjadi tantangan yang dimiliki oleh Terminal Teluk Lamong antara lain: pertumbuhan petikemas di kawasan tanjung perak tumbuh di angka $6 \%$ dari tahun ke tahun, perkembangan teknologi berpeluang meningkatkan efisiensi operasional dengan integrasi data antar-pelabuhan dan meningkatkan kemudahan maupun kualitas pelayanan pelanggan; meningkatnya permintaan khusus dari pelanggan kepada TTL terkait pelayanan yang cepat, tepat, dan akurat; Pelindo 3 dan PGN membuka usaha LNG di TTL; TTL memiliki Lahan yang tersedia masih sekitar 60\% dari total area; dan keinginan pelanggan mendapatkan tarif yang kompetitif dan kualitas layanan yang cepat dan prima.

Faktor eksternal yang menjadi hambatan yang dimiliki oleh Terminal Teluk Lamong antara lain: adanya pemain-pemain baru di dalam industri petikemas, Indonesia saat ini memasuki era disrupsi (kondisi perekonomian dan politik global sangat rawan dan penuh dengan ketidakpastian), terciptanya teknologi-teknologi baru yang berpotensi untuk mengubah peta bisnis di industri petikemas, kualitas layanan, tarif, kehandalan, hinterland dan interkoneksi dari terminal petikemas pesaing, regionalisasi supply chain (produksi dan logistik), dan ketegangan tensi geopolitikal dan perdagangan (perang perdagangan, boikot, dll), ex. Amerika \& China.

Dari hasil yang didapat maka dapat dianalisis sebagian besar responden berpendapat bahwa Terminal Teluk Lamong belum memiliki strategi yang cukup efektif terhadap faktorfaktor eksternal, yang berarti Terminal Teluk Lamong belum cukup kuat dalam merespons ancaman dari luar dan belum cukup memanfaatkan peluang dari faktor yang ada. Jika dicari rata-rata pada bobot matriks EFE maka hasilnya adalah 2.554, di mana bobot tersebut berada pada wilayah rata-rata. 


\section{Internal-Eksternal (IE) Matriks}

Hasil dari perhitungan matriks eksternal dan matriks internal Terminal Teluk Lamong adalah nilai rata-rata EFE 2,554 yang berada pada wilayah menengah, sedangkan nilai ratarata IFE 2,339 yang berada pada wilayah ratarata. Jika melihat gambar matriks eksternal dan internal di atas maka posisi strategi Terminal Teluk Lamong berada pada kuadran V. Menurut David (2006), untuk area kedua terdiri dari sel III, V, atau VII dapat digambarkan sebagai strategi hold and maintain. Strategi yang sesuai untuk tahap hold and maintain adalah market penetration dan product development.

\section{Analisis 3C}

Potensi keuntungan jangka panjang perusahaan dalam suatu industri dapat dilihat dari konsep 3C yang dikemukakan oleh Ohmae untuk bisa lebih kompetitif sehingga membentuk struktur atau daya tarik industri tersebut. Untuk menganalisis daya tarik industri dan daya saing perusahaan, berikut akan dibahas analisis industri dengan menggunakan kerangka 3C.

a. Customer

Suatu perusahaan pada awalnya harus memprediksi sasaran pasar yang akan dituju. Perusahaan tersebut harus terlebih dahulu mengetahui kebutuhan dan keinginan calon pelanggan atau potential customer sehingga perusahaan dapat mempersiapkan produk atau jasa yang sama-sama menguntungkan baik dari pelanggan maupun perusahaan. Customers adalah pelanggan atau orang-orang yang menggunakan jasa yang akan ditawarkan. Perusahaan (TTL) sebaiknya lebih menekankan fokus pada keinginan pelanggan yaitu pada

THE IFE WEIGHTED SCORES

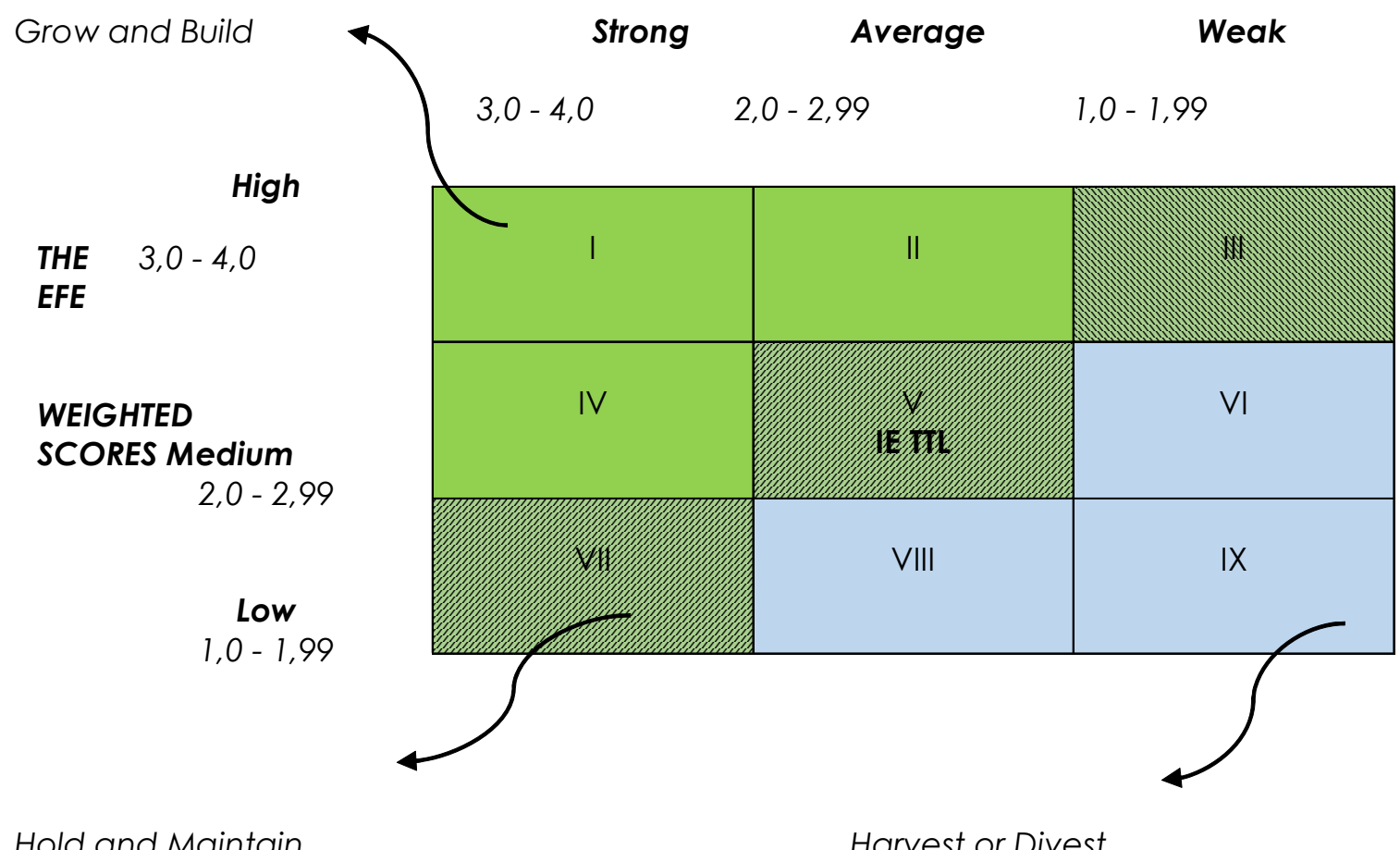

Gambar INTERNAL-EXTERNAL (IE) MATRIX 
proses pelayanan yang cepat pada waktu bongkar muat petikemas.

b. Company

Sebuah usaha pemasaran tidak hanya terpusat pada kegiatan menjual jasa saja, namun diperlukan analisis perusahaan agar dapat mengetahui strategi yang efektif untuk mampu bersaing dengan competitor serta memperoleh laba yang signifikan. Untuk melihat hal tersebut dapat diketahui melalui dua aktivitas yaitu aktivitas utama dan aktivitas utama dan pendukung.

c. Competitors

Setiap usaha pasti memiliki pesaing dalam memasarkan sebuah produk atau layanan yang diberikan. Layaknya sebuah kompetisi, TTL juga berlomba menjadi pemenang di pasar dalam layanan bongkar muat petikemas. Menurut data internal TTL perolehan bongkar muat petikemas dibandingkan competitor sangat kecil sekalipun mengalami kenaikan setiap tahunnya. Market share terbesar masih dikuasai oleh Terminal Petikemas Surabaya (TPS) sebesar 39\% jika dibandingkan TTL hanya sebesar $14 \%$. Dilihat dari selisih yang tidak terlalu jauh sebaiknya perusahaan bisa meningkatkan market share agar bisa mengimbangi kompetitor.

\section{Pilihan Strategi}

Berdasarkan hasil external factor evaluation matrix, bobot rata-rata EFE adalah 2,439, yaitu pada posisi rata-rata. Artinya masih ada potensi bagi industri bongkar muat petikemas untuk tumbuh meskipun ada beberapa hambatan karena pengaruh faktor eksternal lainnya. Hasil ini menggambarkan bahwa pada Terminal Teluk Lamong masih memiliki kesempatan untuk dapat bersaing dalam industri bongkar muat petikemas.
Pemilihan strategi yang tepat merupakan hal yang penting untuk dapat mencapai optimalisasi kinerja perusahaan. Pilihan strategi pada IE Matrix meliputi intensive strategy, integrative strategy, retrenchment atau liquidation. Intensive strategy dapat berupa strategi penetrasi pasar dan pengembangan produk. Sedangkan integrative strategy dapat berupa strategi integrasi ke depan (forward integration) di mana perusahaan melakukan akuisisi terhadap distributor, integrasi ke belakang (backward integration) yaitu perusahaan melakukan akuisisi terhadap supplier, dan integrasi secara horizontal di mana perusahaan melakukan akuisisi terhadap perusahaan pesaing sejenis. Sedangkan saat perusahaan berada pada posisi paling buruk, maka pilihan strategi adalah dengan melakukan penghematan (retrenchment), menjual aset atau melakukan likuidasi untuk dapat mempertahankan kondisi financial perusahaan.

Berdasarkan analisis matriks internal dan eksternal, posisi Terminal Teluk Lamong berada pada area kedua, yaitu kuadran V. Area kedua, yaitu kuadran III, V dan VII merupakan tahap "hold and maintain". Untuk posisi ini, strategi yang cocok diterapkan pada Terminal Teluk Lamong adalah intensive strategy (market penetration). Dalam tahap menjaga dan mempertahankan, posisi perusahaan berada pada kondisi rata-rata, maka perusahaan harus berusaha untuk menumbuhkan lebih lanjut bisnis saat ini, untuk dapat mencapai posisi yang lebih baik dari para pesaing.

\section{SIMPULAN DAN SARAN}

\section{Simpulan}

Dari hasil pembahasan dan analisis, maka dapat ditarik kesimpulan yang akan menjawab tujuan dari penelitian ini. Terminal Teluk La- 
mong berada pada posisi "hold and maintain". Hal ini didasarkan pada pertimbangan faktor internal, faktor eksternal, dan analisis posisi perusahaan dengan menggunakan Internal-External Evaluation Matrix (IE Matrix). Hasil internal factor evaluation (IFE) Terminal Teluk Lamong adalah nilai rata-rata IFE 2,339, yang berada di wilayah rata-rata. Sedangkan hasil eksternal faktor evaluation (EFE) Terminal Teluk Lamong adalah nilai rata-rata EFE 2,554, yang berada di wilayah menengah. Dari hasil IFE dan IFE matrix, maka posisi Terminal Teluk Lamong pada analisis matriks internal eksternal berada pada kuadran V, yaitu pada area II di mana perusahaan berada pada posisi hold and maintain.

Berdasarkan analisis yang telah dilakukan dengan menggunakan matriks internal dan eksternal (IE matrix), maka posisi hold and maintain yang diduduki oleh Terminal Teluk Lamong memiliki beberapa alternatif strategi yang dapat digunakan, yaitu: penetrasi pasar (market penetration). Tujuan dari penetrasi pasar adalah untuk meningkatkan market share Terminal Teluk Lamong, melalui usaha pemasaran yang lebih besar. Strategi pertumbuhan ini fokus pada penjualan layanan yang ada pada pasar yang telah ada sebelumnya. Dengan melakukan penetrasi pasar, maka perusahaan akan mampu menganalisis kondisi persaingan dalam industri tersebut, dan mengukur peluang-peluang potensial pasar secara keseluruhan.

\section{Saran}

Penelitian ini bagi kalangan akademis diharapkan dapat digunakan untuk memperkaya pengetahuan serta melengkapi literatur mengenai konsep strategi bersaing pada perusahaan BUMN khususnya pada bongkar muat petikemas.

\section{DAFTAR RUJUKAN}

Ali, Z. 2000. Metode Penelitian Hukum. Jakarta: Sinar Grafik.

Ali, G., Kerem, T., \& Korkmaz, U. 2012. Application of Combined SWOT and AHP: A Case Study for a Manufacturing Firm. 8th International Strategic Management Conference. Procedia - Social and Behavioral Sciences 58 (2012) 1525-1534.

Al-Refaie, A., Sy. E., Rawabdeh, i., \& Alaween, W. 2016. Integration of SWOT and ANP for Effective Strategic Planning in the Cosmetic Industry. Advances in Production Engineering \& Management, March 2016, pp. 49-58.

Creswell, J.W. 2015. Penelitian Kualitatif dan Desain Riset: Memilih di antara Lima Pendekatan. Yogyakarta: Pustaka Pelajar.

David, F.R. 2002. Strategic Management: Cases. Prentice Hall.

David, Fred. R. 2004. Strategic Management: Concepts and Cases 10th Ed. Prentice Hall.

David, Fred. R. 2006. Manajemen Strategis. Jakarta, DKI Jakarta, Indonesia: Penerbit Salemba Empat.

David, Fred R. 2010. Strategic Management: A Competitive Advantage Approach, Concepts and Cases (13th Edition). London: Prentice Hall International.

David Fred, R. 2011. Strategic Management Manajemen Strategi Konsep, Edisi 12. Jakarta: Salemba Empat.

Eko, H.B. \& R.O. Saut, G. 2017, Manajemen Pelabuhan, Pasca UU No. 17 Tahun 2008 Era Poros Maritim dan Tol Laut. PT Andhika Prasetya Ekawahana.(

Fandy, T. 2006. Manajemen Jasa. Yogyakarta: Andi. 
Gallego-Ayala, J. dan Juízo, D. 2011. Strategic Implementation of Integrated Water Resources Management in Mozambique: An A'WOT Analysis. Physics and Chemistry of the Earth, 36, 1103-1111.

Hill, T. \& Westbrook, R. 1997. SWOT Analysis: It's Time for a Product Recall. Long Range Plan, 30 (1), 46-52.

Hardianto, R.B. 2000. Kajian Strategi Perusahaan PT Perkebunan Negara XI dalam Perspektif SWOT. Karya Tulis Utama Program Magister Manajemen Universitas Airlangga. Tidak diterbitkan.

Ireland, R. Duane, Robert E. Hoskisson, \& Michael A. Hitt. 2009. The Management of Strategy: Concepts and Cases (8 Edition). Ohama: South- Western Cengage Learning.

Jorfi, H., Yaccob, H.F.B., \& Shah, I. M. 2011. Relationships among Strategic Management, Strategic Behaviors, Emotional Intelligence, IT-business Strategic Alignment, Motivation, and Communication Effectiveness. International Journal of Business and Management, 30-37.

Kusdihandari, Susi. 2003. Kajian Strategi pada PT Bank Mandiri (Persero) Cabang Hub Basuki Rahmat Surabaya dengan Menggunakan Perspektif SWOT. Karya Tulis Utama Program Magister Manajemen Universitas Airlangga. Tidak diterbitkan.

Kirovska, Z. 2011. Strategic Management within the Tourism and the World Globalization. Journal of Economics, 2 (1): 69-76.

Moleong, L.J. 2014. Metode Penelitian Kualitatif, Edisi Revisi. Bandung: PT Remaja Rosdakarya.

Nidhi, V.A. \& Preetvanti, S. 2016. Integrated Analytical Hierarchy Process with SWOT Analysis for Women Education. Interna- tional Journal of Management and Applied Science, Issn: 2394-7926.

Ohmae, K. 1995. The End of the Nation State, The Rice of Regional Economic. New York/ London: The Free Press.

Porter, M.E. 1985. Competitive Advantage: Creating and Sustaining Superior Performance. New York: The Free Press.

Prasetyadi. 2015. Perancangan Strategis Performance Management di PT Terminal Teluk Lamong. Surabaya: Magister Management, Ekonomi dan bisnis, Universitas Airlangga.

PT Pelabuhan Indonesia III (Persero). 2014. Rencana Jangka Panjang Perusahaan (RJPP) 2014-2018.

PT Terminal Teluk Lamong. 2015. Rencana Jangka Panjang Perusahaan (RJPP) 2015-2019.

PT Terminal Teluk Lamong. 2017. Rencana Kerja dan Anggaran Perusahaan (RKAP) 20172018.

Putu. Y., Okta. R., Ahmadi. S., \& Okol. S.S. 2017. Feasibility Analysis of Naval Base Relocation Using SWOT and AHP Method to Support Main Duties Operation. Journal of Defense Management. DOI: 10. 4172/2167-0374.1000160.

Pearce II, J.A. \& Robinson. R.B.Jr. 2008. Manajemen Strategis 10. Jakarta: Salemba Empat.

Rangkuti. F. 2015. Analisis SWOT: Teknik Membedah Kasus Bisnis. Jakarta: Gramedia Pustaka Utama.

Sampik. K.T. \& Chriswahyudi. 2017. Perencanaan Strategi Pemasaran dengan Pendekatan Matrik IE, SWOT, dan AHP untuk Mendapatkan Alternatif Strategi Prioritas. Seminar Nasional Sains dan Teknologi.

Sekaran, U. 2017. Metode Penelitian untuk Bisnis Pendekatan Pengembangan-Keablian. Jakarta: Salemba Empat. 
Swayne, L., Duncan, W.J., \& Ginter, P.M. 2006. Strategic Management of Health Care Organizations. John Wiley \& Sons.

Sugiyono. 2017. Metode Penelitian Kualitatif: untuk Penelitian yang Bersifat: Eksploratif, Enterpretatif, Interaktif, dan Konstruktif. Bandung: Alfabeta.

Sutari. 2013. Analisis Swot dalam Strategi Pengembangan Cabang Bank Mandiri di Daerah Pantura Kabupaten Lamongan. Karya Tulis Utama Program Magister Manajemen Universitas Airlangga. Tidak diterbitkan.

Stoner, J. A.F., Freeman, R., Edward, G. JR, \& Daniel, R. 2005, Manajemen, Jilid I, PT Bhuana Ilmu Populer.

Thomas L. Saaty. 1980. The Analytic Hierarchy Process. New York: McGraw-Hill.

Umar, H. 2002. Riset Pemasaran dan Perilaku Konsumen. Jakarta: PT Gramedia Pustaka Utama.

Wickramasinghe, V. \& Takano, S. 2010. Application of Combined SWOT and Analytic Hierarchy Process (AHP) for Tourism Re- vival Strategic Marketing Planning: A Case of Sri Lanka Tourism. Journal of the Eastern Asia Society for Transportation Studies, Vol. 8, pp. 954-969.

Wheelen, T.L. \& Hunger, J.D. 1995. Strategic Management and Business Policy, Singapore: Addison Wessley.

Worsfold, K., Worsfold, J., \& Bradley, G. 2007. Interactive Effects of Proactive and Reactive Service Recovery Strategies: The Case PF Rapport and Compensation. Journal of Applied Social Psychology.

York, K.M. \& Miree, C.E. 2012. Searching for Trace Evidence of Strategic Management Decisions: Using Organizational Theory to Understand the Competitive Environment. Journal of Strategic Management Education, 8(2): 147-172.

Yuksel, I., Degdeviren, M. 2007. Using the Analytical Network Process (ANP) in a SWOT Analysis- A Case Study for a Textile Firm, Information Sciences, 177. pp. 3364-3382. 